\title{
Comparison of Audiometric Findings with Internet-based Hearing Screening Tests and the Relationship with Other Associated Factors in Adults
}

\author{
Chan Nyein ${ }^{1}$, Sherly Deborah ${ }^{1}$, Dhanalekshmi Unnikrishnan \\ Meenakshi ${ }^{2}$ and Usha Kumari ${ }^{1 *}$ \\ ${ }^{1}$ Unit of Physiology, Faculty of Medicine, AIMST University, Kedah, Malaysia \\ ${ }^{2}$ College of Pharmacy, National University of Science and Technology, Oman \\ *Corresponding Author: Usha Kumari, Unit of Physiology, Faculty of Medicine, \\ AIMST University, Kedah, Malaysia.
}

Received: November 02, 2020

Published: November 27, 2020

(C) All rights are reserved by Usha Kumari., et al.

\begin{abstract}
Hearing loss is one of the most challenging problems confronting medicine since it may affect the personality so adversely that it can lower someone's quality of life. The aim of the study is to establish the validity of internet based hearing test. The hearing status of adults was evaluated by comparing audiometric findings and internet-based hearing screening test along with questionnaires to assess the potential risk factors associated with hearing loss. This cross-sectional study included 256 participants (18 to 40 years of both genders) by simple random sampling method, of which 245 had completed all the procedures. The study was carried out by using Pure Tone Audiometry (PTA), two internet-based speech-in-noise tests: internet test 1 (HearCom Digit Triplet Test offered by MED-EL) and internet test 2 (Speech in Noise Test by National Health Service) and survey questionnaires. Descriptive statistics and Pearson Chi-Square test was used to analyze the data. All presentations and data evaluations were carried out by using SPSS version 21.0. The prevalence of hearing loss was $26.1 \%$ with PTA; $5.3 \%$ with internet test 1 and $47.3 \%$ with internet test 2 . Among two internet-based hearing screening tests, internet test 1 is significantly correlated with PTA averages ( $p<0.05,2$-tailed) and the correlation coefficients showed weak association between the different tests. The study showed a significant correlation between audiograms and internet-based hearing tests and significant differences with associated factors as evaluated by using an extensive questionnaire. This study suggests that internet-based hearing test is feasible to screen for hearing status online and the data are of great value in applications and for advanced studies. Though an internet-based hearing test cannot replace a clinical pure-tone audiogram, it is a feasible screening tool for hearing ability in a large-scale population.
\end{abstract}

Keywords: Internet Based Hearing Test; Audiometry; Hearing Loss; Noise; Pure Tone; Speech

\section{Introduction}

According to WHO global estimates there is a high prevalence of hearing loss in the Asia-Pacific region. Around 466 million people worldwide have disabling hearing loss and 34 million of these are children and it was estimated that by 2050 over 900 million people will have disabling hearing loss [1]. The 2017 World Health Assembly announced their resolution to prevent deafness and hearing loss and device strategies for improved service provision, especially in low and middle income countries [2]. However, the prevalence of hearing loss in Malaysia seems to be more than the WHO estimate. There are many reports of hearing studies con- ducted in Malaysia. One of the cross-sectional studies conducted at six quarries in a north-eastern state of Malaysia assessed the knowledge, attitude and practice towards noise-induced hearing loss. Poor knowledge, attitude and practice scores of the respondents and a high prevalence of noise-induced hearing loss (57\%) was shown to be contributed by factors such as poor practice towards noise level and old age [3,4]. Early hearing effects related to Personal Listening Device (PLD) usage were evaluated in 35 young adult Malaysian PLD users (aged 18-30 years). This study used extended high-frequency audiometry and otoacoustic emissions and results indicated the presence of an early stage of hearing dam- 
age in the PLD user group [5]. Smartphone applications are used as a measurement tool in recent days for hearing test and the two broad categories are clinical (medically regulated) and consumer apps [6].

Recent study based on mobile based approach of screening test reported that smartphone-based self-hearing test demonstrated high concordance with conventional PTA in a sound-treated booth among school children [7]. A study conducted on grade five school children in Malaysia showed 15\% prevalence of mild hearing loss among 257 primary school children [8]. As this problem could affect their academic performance, they have highly recommended the assessment of hearing on every child especially to those who have poor academic achievement. High prevalence of hearing loss was found in both adults and children pointed out that hearing screening should routinely be carried out.

Hearing impairment is most accurately measured by a clinical pure-tone audiogram but this method is not suitable for largescale, population-based epidemiological studies because it requires trained personnel as well as the participants should visit a clinic. An alternative approach to measuring hearing ability is selfestimation through questionnaires but the correlation of questionnaires to clinical audiometric tests is different.

With advances in computer technology, low-cost computerbased hearing screening test has been developed. The evolutions of eHealth and telemedicine have shifted focus from patients coming to the hearing clinic for hearing health evaluation towards the possibility of evaluating the hearing status remotely at home. A quick-automated self-test to detect hearing loss is highly advantageous for large-scale population. For gross hearing status evaluation, internet-based hearing screening tests are valid, reliable and an alternative to Pure Tone Audiometry (PTA). Thus, this study was conducted to determine hearing status in adults comparing the audiometric findings with internet-based hearing screening test. To date, there are no known reports on the comparison of PTA with internet based hearing screening test in Malaysia. The study was therefore to compare the results of hearing status in adults by using PTA with that of online internet-based hearing tests. In addition, the potential risk factors associated with hearing loss were assessed by using questionnaires. The main objective is to compare the results obtained with audiometer and internet-based hearing screening test on hearing status of adults.

\section{Subjects and Methods}

This cross-sectional study was conducted at the Physiology Laboratory of a private Malaysian University with ethical approval. This study involved 256 participants aged between 18 to 40 years (both male and female) by simple random sampling method. A portable pure tone screening audiometer (model Maico MA 39, USA) was used for hearing screening. Two internet based hearing screening tests are internet test 1 (HearCom Digit Triplet Test) and internet test 2 (Speech in Noise Test by National Health Service). In this study, two sets of questionnaires (Likert Scale) were used. One questionnaire consisted of 36 questions concerning sociodemographi, past medical history and exposure to noise, and the other questionnaire "Youth Attitude to Noise Scale" (YANS) which consisted of 19 questions [9].

Visual examination of the ear canal was conducted by the investigator to ensure normal anatomy and no presence of debris. The average hearing threshold levels of the total study population was analysed. To simplify the results, hearing loss was evaluated using pure-tone averages calculated for $0.5,1,2$ and $4 \mathrm{kHz}\left(\mathrm{PTA}_{0.5,1,2,4}\right)$ and for the noise-sensitive frequencies 3,4 and $6 \mathrm{kHz}\left(\mathrm{PTA}_{3,4,6}\right)$.

\section{Statistical analyses}

Descriptive statistics was used to examine the collected data in terms of mean, standard deviation and frequencies. Simple random sampling and a total of 256 participants included in the data analyses. The Pearson Chi-Square test was used to determine the age and gender and for specific comparisons between the audiometric findings and internet-based hearing screening results. Bivariate correlation coefficients was tested by using Spearman's rho for internet-based hearing screening test and PTA-values. Error bars in the graph represents standard deviation. All presentations and data evaluations were carried out by using SPSS version 21.0.

\section{Results}

A total of 256 participants aged between 18-40 years (mean age $21.5 \pm 4.6)$ had participated in the study, however, only $245(95.7 \%)$ completed all the steps. Among 245 participants (104 males and 141 females), 220 were students (89.8\%) and the rest were staffs (10.2\%). Distribution and association between age groups and gender of participants $(\mathrm{p}=0.083)$ are showed in table 1 . Participants with different ethnicity were not evenly distributed in different age groups yielding no gender difference in all groups $(\mathrm{p}=0.08)$. Data of personal habits, medical history and exposure to noise data

Citation: Usha Kumari., et al. "Comparison of Audiometric Findings with Internet-based Hearing Screening Tests and the Relationship with Other Associated Factors in Adults”. Acta Scientific Medical Sciences 4.12 (2020): 103-113. 
were summarized using descriptive statistics. Socio-demographic profiles of 245 participants showed that most of them i.e. $63.7 \%$ were Chinese followed by Indians, Malay and others $(25.7 \%, 6.9 \%$ and $3.7 \%$ respectively). Mean age was $21.5 \pm 4.6$ (104 males, 141 females). While a few (4.1\%) had a history of smoking and drinking alcohol (10.6\%), none of them had any history of drug abuse and $4.1 \%$ had a past history of ear problem.

Results of the YANS were divided into three categories based on the quartiles of the sum of the entire YANS scale. The $25 \%$ of the sample in the lower quartile (0.0000_2.8420) were individuals who could be characterized as having an anti-noise attitude. $50 \%$ of the sample in the two middle quartiles (2.8421_3.5262) were characterized as having a neutral attitude, whereas the remaining 25\% in the upper quartile (3.5263_5.0000) had pro-noise attitudes. Regarding the internal reliability of YANS questionnaire, Cronbach's alpha for the entire scale was 0.533. F1 showed the highest Cronbach's alpha (0.716), which consistently decreased throughout the other factors (F2, F3, F4). In table 2, mean and correlations between the factors and the entire scale are presented along with Cronbach's alpha.

\begin{tabular}{|c|c|c|c|c|}
\hline Description & \multicolumn{3}{|c|}{ Age group } & \multirow[b]{2}{*}{ Total } \\
\hline Gender & $\begin{array}{c}I \\
(\leq 20 \\
\text { years })\end{array}$ & $\begin{array}{c}\text { II } \\
(21-30 \\
\text { years })\end{array}$ & $\begin{array}{c}\text { III } \\
(31-40 \\
\text { years })\end{array}$ & \\
\hline Male & 62 & 31 & 11 & 104 \\
\hline Female & 103 & 27 & 11 & 141 \\
\hline Total & 165 & 58 & 22 & 245 \\
\hline
\end{tabular}

Table 1: Distribution and association between age groups and gender of participants.

Pearson Chi-Square $=4.990(2), \mathrm{p}=0.083$.

\begin{tabular}{|l|c|c|c|c|c|}
\hline Items & $\mathbf{F 1}(\mathbf{1 9 , 1 8 , 1 3 , 1 5 , 3 , 1 2 )}$ & $\mathbf{F 2}(\mathbf{9 , 4 , 1 , 1 0 , 6 , 8 )}$ & $\mathbf{F 3 ( 1 7 , 1 1 , 1 4 , 1 6 )}$ & $\mathbf{F 4 ( 7 , 5 , 2 )}$ & $\begin{array}{c}\text { YANS } \\
\text { (integer) }\end{array}$ \\
\hline F1 $(19,18,13,15,3,12)$ & 1 & - & - & - & - \\
\hline F2 $(9,4,1,10,6,8)$ & -.051 & 1 & - & - & - \\
\hline F3(17,11,14,16) & -.066 & $0.309^{* *}$ & 1 & - & - \\
\hline F4(7,5,2) & 0.040 & 0.110 & $0.250^{* *}$ & 1 & - \\
\hline YANS(integer) & $0.533^{* *}$ & $0.581^{* *}$ & $0.608^{* *}$ & $0.527^{* *}$ & 1 \\
\hline Mean & 2.50 & 2.75 & 2.64 & 2.82 & 2.65 \\
\hline Cronbach's alpha & 0.716 & 0.597 & 0.584 & 0.408 & 0.533 \\
\hline **. Correlation is significant at the 0.01 level (2-tailed) & & & \\
\hline
\end{tabular}

Table 2: Correlations between the factors and the entire YANS, Mean and Cronbach's alpha for each factor and the entire instrument.

Results of the pure tone audiograms were divided into normal, minor, moderate and severe hearing loss according to the definition by WHO [10] as shown in table 3. For the comparison with internet-based hearing screening (speech-in-noise) tests, the pure tone averages were grouped into $\mathrm{PTA}_{0.5,1,2,4}$ (important for speech intelligibility) and $\mathrm{PTA}_{3,4,6}$ (noise-sensitive frequencies). PTA results for each groups are calculated. Internet test 1 (HearCom digit triplet test offered by MED-EL) results showed 232 out of 245 (94.7\%) normal, 5 out of 245 (2\%) may be below normal and 8 out of 245 (3.3\%) below normal. Internet test 2 (offered by NHS) results showed 129 out of 245 (52.7\%) normal, 98 out of 245 (40\%) little below normal and 18 out of 245 (7.3\%) below normal. Comparison results of the internet test 1 and test 2 showed statistically significant differences between normal and hearing loss $(p<0.05)$. Internet-based hearing tests were compared with puretone thresholds. The pure-tone thresholds PTA $_{0.5,1,2,4}$ (important for speech intelligibility) and $\mathrm{PTA}_{3,4,6}$ (noise-sensitive frequencies) were used to compare with the internet-based hearing tests. In table 4, Chi-square test showed no statistical difference of internet test 1 between age group and $\mathrm{PTA}_{3,4,6^{\circ}}\left(\chi^{2}=0.417(2), \mathrm{p}=0.812\right)$. In PTA $_{0.5,1,2,4^{\prime}} 228$ had normal and 17 had hearing loss while 232 showed normal and 13 showed hearing loss on the internet test 1. The Chi-Square test showed no statistical difference between internet test 1 and PTA ${ }_{0.5,1,2,4}$ for different age groups. $\left(\chi^{2}=3.918(2)\right.$, $\mathrm{p}=0.141)$. Results of the hearing test with pure tone audiogram $\left(\mathrm{PTA}_{0.5,1,2,4}\right.$ and $\left.\mathrm{PTA}_{3,4,6}\right)$ in comparison to the internet test 2 for age groups are shown in table 4 and table 5 respectively. Mean audiogram of left and right ears for specific age group are displayed in figures 1-6.

\begin{tabular}{|l|c|}
\hline & Frequency (\%) \\
\hline Normal & $181(73.9 \%)$ \\
\hline Minor Hearing loss & $61(24.9 \%)$ \\
\hline Moderate Hearing loss & $2(0.8 \%)$ \\
\hline Severe Hearing loss & $1(0 / 4 \%)$ \\
\hline Total & $245(100 \%)$ \\
\hline
\end{tabular}

Table 3: Number and percentage of hearing loss according to WHO classification $(0.125,0.25,0.5,1,2,3,4,6,8 \mathrm{kHz})$. 


\begin{tabular}{|c|c|c|c|c|c|c|c|c|}
\hline \multirow{2}{*}{\multicolumn{3}{|c|}{$\begin{array}{l}\text { Description } \\
\text { Normal } \\
\text { Hearing loss }\end{array}$}} & \multicolumn{2}{|c|}{$\begin{array}{c}\text { Internet test1 } \\
\text { PTA }_{3,4,6} \\
\end{array}$} & \multirow{3}{*}{$\begin{array}{c}\text { Total } \\
\text { Hearing loss } \\
158\end{array}$} & \multicolumn{2}{|c|}{$\begin{array}{c}\text { Internet test2 } \\
\text { PTA }_{0.5,1,2,4}\end{array}$} & \multirow{3}{*}{$\begin{array}{r}\text { Total } \\
87\end{array}$} \\
\hline & & & & Normal & & & & \\
\hline \multirow[t]{5}{*}{ Normal } & \multirow{3}{*}{$\begin{array}{l}\text { Age group } \\
\text { (years) }\end{array}$} & $\mathrm{I}(\leq 20)$ & 149 & 9 & & 78 & 9 & \\
\hline & & II $(21-30)$ & 54 & 2 & 56 & 37 & 0 & 37 \\
\hline & & III $(31-40)$ & 16 & 2 & 18 & 5 & 0 & 5 \\
\hline & \multicolumn{2}{|c|}{ Total } & 219 & 13 & 232 & 120 & 9 & 129 \\
\hline & \multicolumn{2}{|c|}{ Pearson Chi-Square } & $1.472^{\mathrm{a}}$ & 2 & 0.479 & $4.671^{\mathrm{a}}$ & 2 & 0.097 \\
\hline \multirow{5}{*}{$\begin{array}{l}\text { Hearing } \\
\text { loss }\end{array}$} & \multirow{3}{*}{$\begin{array}{l}\text { Age group } \\
\text { (years) }\end{array}$} & $\mathrm{I}(\leq 20)$ & 5 & 2 & 7 & 72 & 6 & 78 \\
\hline & & II $(21-30)$ & 1 & 1 & 2 & 19 & 2 & 21 \\
\hline & & III $(31-40)$ & 4 & 0 & 4 & 17 & 0 & 17 \\
\hline & \multicolumn{2}{|c|}{ Total } & 10 & 3 & 13 & 108 & 8 & 116 \\
\hline & \multicolumn{2}{|c|}{ Pearson Chi-Square } & $2.136^{\mathrm{b}}$ & 2 & 0.344 & $1.562^{\mathrm{b}}$ & 2 & 0.458 \\
\hline \multirow[t]{4}{*}{ Total } & \multirow{3}{*}{$\begin{array}{l}\text { Age group } \\
\text { (years) }\end{array}$} & $\mathrm{I}(\leq 20)$ & 154 & 11 & 165 & 150 & 15 & 165 \\
\hline & & II $(21-30)$ & 55 & 3 & 58 & 22 & 0 & 22 \\
\hline & & III (31 - 40) & 20 & 2 & 22 & 228 & 17 & 245 \\
\hline & \multicolumn{2}{|c|}{ Total } & 229 & 16 & 245 & $3.918^{\mathrm{c}}$ & 2 & 0.141 \\
\hline
\end{tabular}

Table 4: Comparative table of $\mathrm{PTA}_{3,4,6}$ and Internet test 1 and 2 for age groups.

\begin{tabular}{|c|c|c|c|c|c|}
\hline \multirow{2}{*}{\multicolumn{3}{|c|}{$\begin{array}{c}\text { Internet test } 2 \\
\text { Normal } \\
\text { Hearing loss }\end{array}$}} & \multicolumn{2}{|c|}{ PTA $_{3,4,6}$} & \multirow[b]{2}{*}{ Total } \\
\hline & & & & & \\
\hline \multirow[t]{5}{*}{ Normal } & \multirow[t]{3}{*}{ Age group (years) } & $\mathrm{I}(\leq 20)$ & 80 & 7 & 87 \\
\hline & & II $(21-30)$ & 35 & 2 & 37 \\
\hline & & III (31 - 40) & 5 & 0 & 5 \\
\hline & \multicolumn{2}{|c|}{ Total } & 120 & 9 & 129 \\
\hline & \multicolumn{2}{|c|}{ Pearson Chi-Square } & $0.669^{\mathrm{a}}$ & 2 & 0.716 \\
\hline \multirow[t]{5}{*}{ Hearing loss } & \multirow[t]{3}{*}{ Age group (years) } & $\mathrm{I}(\leq 20)$ & 74 & 4 & 78 \\
\hline & & II $(21-30)$ & 20 & 1 & 21 \\
\hline & & III $(31-40)$ & 15 & 3 & 17 \\
\hline & \multicolumn{2}{|c|}{ Total } & 109 & 8 & 116 \\
\hline & \multicolumn{2}{|c|}{ Pearson Chi-Square } & $1.157^{\mathrm{b}}$ & 2 & 0.561 \\
\hline \multirow[t]{5}{*}{ Total } & \multirow[t]{3}{*}{ Age group (years) } & $\mathrm{I}(\leq 20)$ & 154 & 11 & 165 \\
\hline & & II $(21$ - 30) & 55 & 3 & 58 \\
\hline & & III (31 - 40) & 20 & 3 & 22 \\
\hline & \multicolumn{2}{|c|}{ Total } & 229 & 17 & 245 \\
\hline & \multicolumn{2}{|c|}{ Pearson Chi-Square } & $0.417^{\mathrm{c}}$ & 2 & 0.812 \\
\hline
\end{tabular}

Table 5: Comparative table of $\mathrm{PTA}_{3,4,6}$ and Internet test 2 for age groups. 


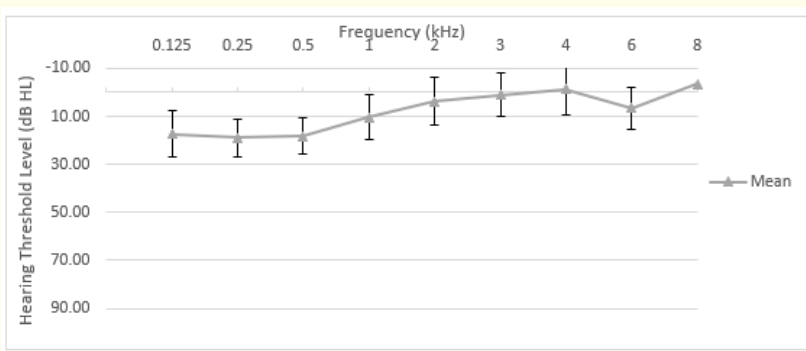

Figure 1: Audiometric thresholds of the left ears (LE) for the age group I ( $\leq 20$ years). (Error bars represent standard deviation)

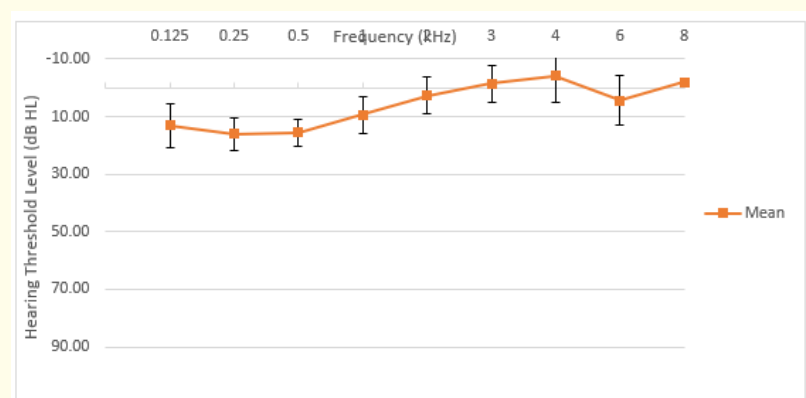

Figure 2: Audiometric thresholds of the right ears (RE) for the age group I ( $\leq 20$ years). (Error bars represent standard deviation)

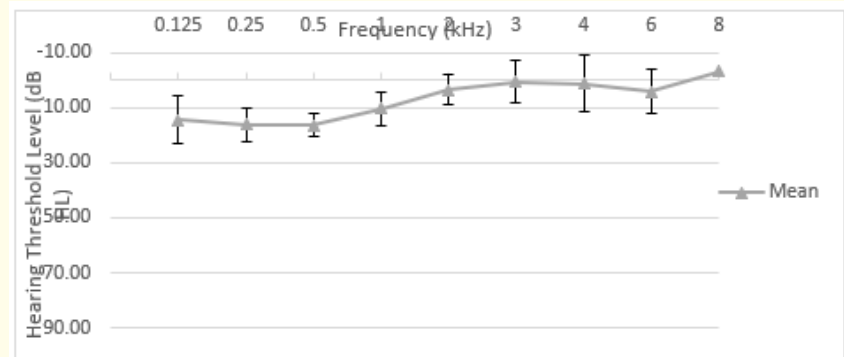

Figure 3: Audiometric thresholds of the left ears (LE) for the age group II (21-30 years). (Error bars represent standard deviation)

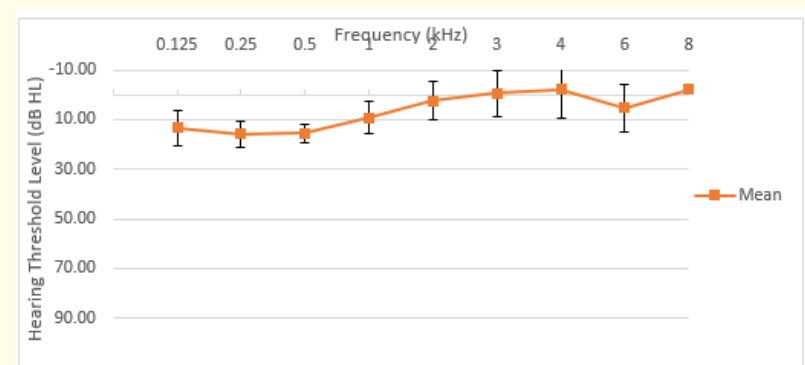

Figure 4: Audiometric thresholds of the right ears (RE) for the age group II (21-30 years). (Error bars represent standard deviation)

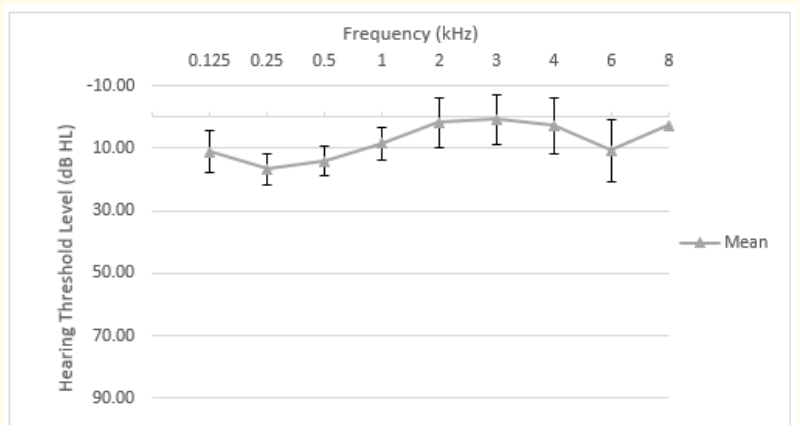

Figure 5: Audiometric thresholds of the left ears (LE) for the age group III (31-40 years). (Error bars represent standard deviation)

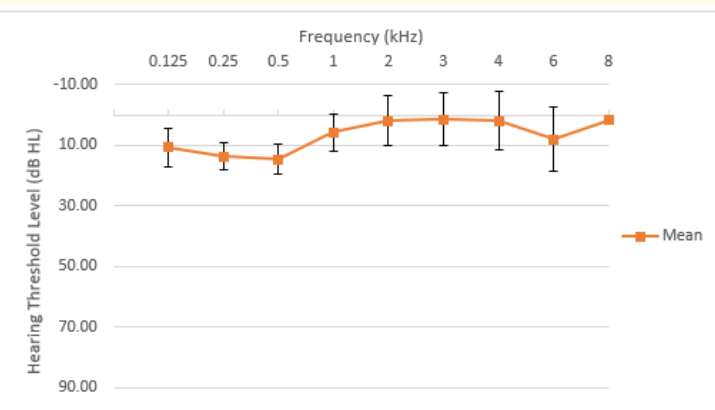

Figure 6: Audiometric thresholds of the right ears (RE) for the age group III (31-40 years). (Error bars represent standard deviation).

Results of the hearing test with pure tone audiogram ( $\mathrm{PTA}_{0.5,1,2,4}$ and $\mathrm{PTA}_{3,4,6}$ ) in comparison to the internet test 1 for gender is shown in table 6 and table 7 respectively. In PTA $_{0.5,1,2,4}$, 228 had normal hearing and 17 had hearing loss while 232 showed normal hearing and 13 showed hearing loss with the internet test 1 . The ChiSquare test showed no statistical difference between internet test 1 and $\mathrm{PTA}_{0.5,1,2,4}$ for gender. (Fisher's exact test, $\mathrm{p}=0.129$ ). In $\mathrm{PTA}_{3,4,6^{\prime}}$ 229 had normal and 16 had hearing loss while 232 showed normal and 13 showed hearing loss on the internet test 1 . For gender, Chisquare test showed no statistical difference between internet test 1 and $\mathrm{PTA}_{3,4,6}$ in table 7. (Fisher's exact test, $\mathrm{p}=0.605$ ). Results of the hearing test with pure tone audiogram $\left(\mathrm{PTA}_{0.5,1,2,4}\right.$ and $\left.\mathrm{PTA}_{3,4,6}\right)$ in comparison to the internet test 2 for gender showed that 129 was normal and 116 had hearing loss. Thus, internet test 2 showed higher percentage of hearing loss than PTA and internet test 1 . The Chi-square test showed no statistical difference between internet test 2 and PTA ${ }_{0.5,1,2,4}$ for gender. (Fisher's exact test, $\mathrm{p}=0.129$ ).

Comparison of $\mathrm{PTA}_{3,4,6}$ with internet test 2 showed 129 normal and 116 hearing loss. The $\chi^{2}$ test showed no statistical difference of genders between internet test 2 and $\mathrm{PTA}_{3,4,6}$ in table 7. (Fisher's exact test, $\mathrm{p}=0.605$ ). 


\begin{tabular}{|c|c|c|c|c|c|}
\hline \multirow{2}{*}{\multicolumn{3}{|c|}{$\begin{array}{c}\text { Internet test } 1 \\
\text { Normal } \\
\text { Hearing loss }\end{array}$}} & \multicolumn{2}{|c|}{ PTA $_{0.5,1,2,4}$} & \multirow[b]{2}{*}{ Total } \\
\hline & & & \multirow[b]{2}{*}{93} & \multirow[b]{2}{*}{3} & \\
\hline \multirow[t]{4}{*}{ Normal } & \multirow[t]{2}{*}{ Gender } & Male & & & 96 \\
\hline & & Female & 125 & 11 & 136 \\
\hline & \multicolumn{2}{|c|}{ Total } & 218 & 14 & 232 \\
\hline & \multicolumn{2}{|c|}{ Fisher's Exact Test } & \multicolumn{3}{|c|}{0.163} \\
\hline \multirow{4}{*}{$\begin{array}{l}\text { Hearing } \\
\text { loss }\end{array}$} & \multirow[t]{2}{*}{ Gender } & Male & 7 & 1 & 8 \\
\hline & & Female & 3 & 2 & 5 \\
\hline & \multicolumn{2}{|c|}{ Total } & 10 & 3 & 13 \\
\hline & \multicolumn{2}{|c|}{ Fisher's Exact Test } & \multicolumn{3}{|c|}{0.510} \\
\hline \multirow[t]{4}{*}{ Total } & \multirow[t]{2}{*}{ Gender } & Male & 100 & 4 & 104 \\
\hline & & Female & 128 & 13 & 141 \\
\hline & \multicolumn{2}{|c|}{ Total } & 228 & 17 & 245 \\
\hline & \multicolumn{2}{|c|}{ Fisher's Exact Test } & \multicolumn{3}{|c|}{0.129} \\
\hline
\end{tabular}

Table 6: PTA ${ }_{05,1,2,4}$ Vs Internet test 1.

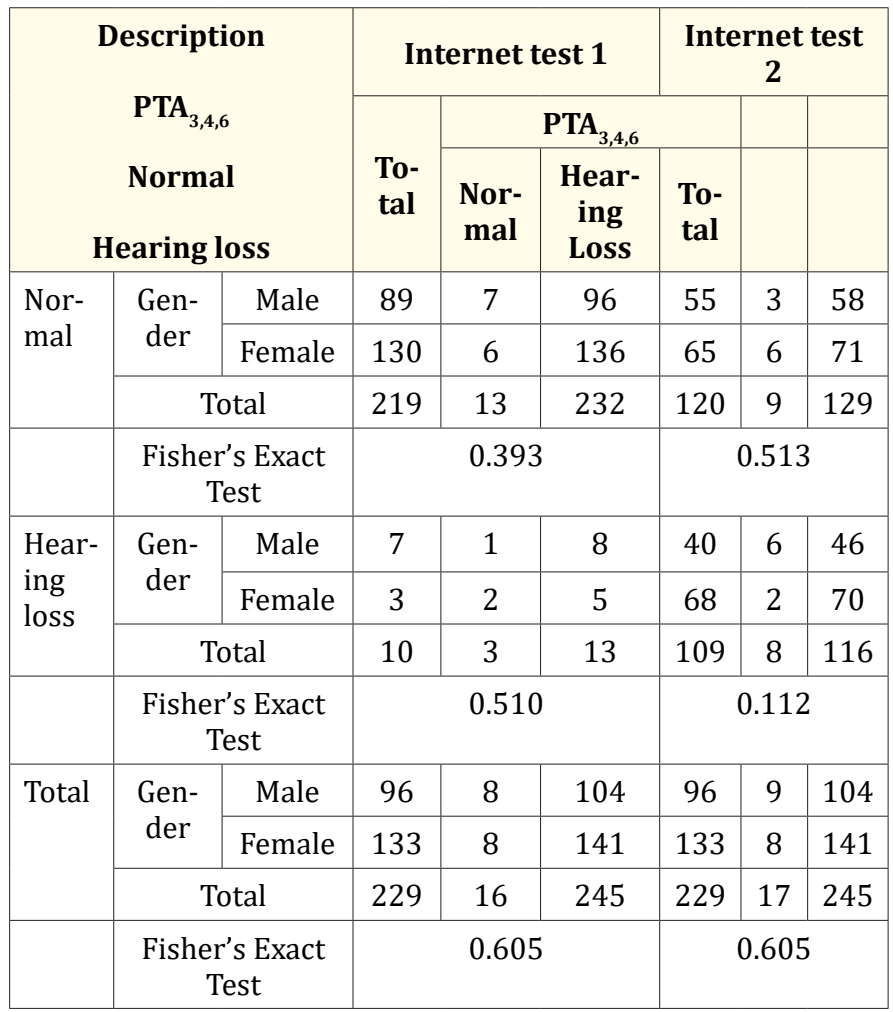

Table 7: PTA ${ }_{3,4,6}$ Vs Internet test 1 and 2.

Other associated factors (personal habits, medical history and exposure to noise) were measured using the questionnaire and
Chi-square test was done to find the relationship between two categorical variables. Personal habits (alcohol drinking, regular physical activity, performed hearing screening test) showed no significant difference between normal and hearing loss in both PTA and internet-based hearing screening test. The relationship between PTA and internet-based hearing screening test for drug abuse was not available because there were no subjects with drug abuse in this study. The Chi-square test showed that internet test 2 showed statistically significant difference with PTA $_{3,4,6}$ among smoking and hearing loss $(\mathrm{p}=0.018)$ as shown in table 8. Participants with medical history of diabetes and hypertension were very few in the study. Therefore, Chi-square test could not be used for these parameters. In table 8 , normal hearing with internet test 2 showed significant difference with normal hearing with PTA $_{3,4,6}$ (ear use for mobile phone).

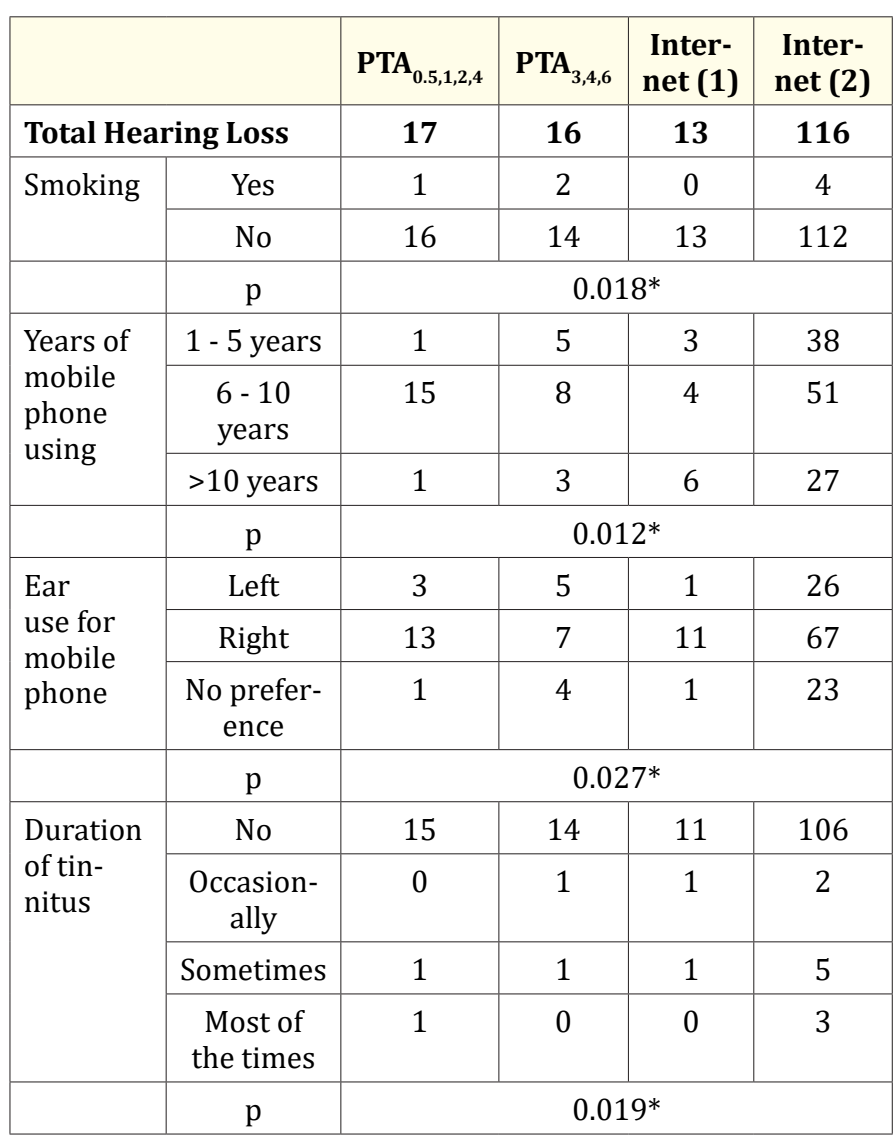

Table 8: Significant findings between PTA averages and internet-based hearing screening tests.

Validity of the internet-based hearing test was related to the correlation between the results of the hearing tests and other pa- 
Comparison of Audiometric Findings with Internet-based Hearing Screening Tests and the Relationship with Other Associated Factors in Adults

rameters of study. The p-value for the Fisher's exact test revealed statistically significant difference $(\mathrm{p}=0.05)$ between normal and hearing loss for internet test 1 and PTA $_{0.5,1,2,4^{*}}$. For internet test 1 and PTA $_{3,4,6}$, the p-value for the Fisher's exact test revealed statistically significant difference $(p=0.04)$ between normal and hearing loss, shown in table 9. The Chi-square test showed no statistically significant difference between normal and hearing loss for internet test 2 , shown in table 9 .

\begin{tabular}{|l|c|c|c|c|c|c|}
\hline $\begin{array}{l}\text { Internet } \\
\text { Test }\end{array}$ & \multicolumn{2}{|c|}{ Internet Test 1 } & \multicolumn{2}{|c|}{ Internet Test 2 } & \multicolumn{2}{|c|}{ Internet Test 2 } \\
\hline PTA & \multicolumn{2}{|c|}{ PTA $_{\mathbf{3}, \mathbf{4}, \mathbf{6}}$} & \multicolumn{2}{|c|}{ PTA $_{\mathbf{0 . 5 , 1 , 4}}$} & \multicolumn{2}{c|}{ PTA $_{\mathbf{3 , 4}}$} \\
\hline $\begin{array}{c}\text { Nor- } \\
\text { mal }\end{array}$ & $\begin{array}{c}\text { Hear- } \\
\text { ing loss }\end{array}$ & $\begin{array}{c}\text { Nor- } \\
\text { mal }\end{array}$ & $\begin{array}{c}\text { Hear- } \\
\text { ing loss }\end{array}$ & $\begin{array}{c}\text { Nor- } \\
\text { mal }\end{array}$ & $\begin{array}{c}\text { Hearing } \\
\text { loss }\end{array}$ \\
\hline Normal & 219 & 3 & 120 & 9 & 120 & 9 \\
\hline $\begin{array}{l}\text { Hearing } \\
\text { loss }\end{array}$ & 10 & 13 & 108 & 8 & 109 & 7 \\
\hline Total & 229 & 16 & 228 & 17 & 229 & 16 \\
\hline $\begin{array}{l}\text { Fisher's } \\
\text { Exact Test }\end{array}$ & $\mathrm{p}=0.04$ & $\mathrm{p}=1.000$ & $\mathrm{p}=0.80$ \\
\hline
\end{tabular}

Table 9: Comparison of internet test 1, 2 and $\mathrm{PTA}_{3,4,6}$ and $\mathrm{PTA}_{0.5,1,2,4}$

In addition, the relationship of the two internet-based hearing tests (speech-in-noise test) and pure-tone thresholds were assessed. Non-parametric Spearman correlation coefficients between the different internet-based hearing tests were calculated. Table 10 showed the correlation coefficients of internet-based hearing test (internet test 1 and test 2) and the pure-tone averages PTA $_{0.5,1,2,4}$ (important for speech intelligibility) and PTA $_{3,4,6}$ (noise-sensitive frequencies). The correlation between internet test 1 results and PTA were all statistically significant $(\mathrm{p}<0.05)$ and showed different degrees of association as shown in table 10. However, internet test 2 results and PTA showed no significant association. Sensitivity and specificity of the internet test in relation to PTA was calculated and internet test 1 showed higher sensitivity and specificity than internet test 2 and the results are shown in table 11.

\begin{tabular}{|l|c|c|c|c|}
\hline $\begin{array}{l}\text { Spearman's } \\
\text { rho }\end{array}$ & $\begin{array}{c}\text { Internet test } \\
\text { 1 MED-EL }\end{array}$ & $\begin{array}{c}\text { Internet } \\
\text { test 2 NHS }\end{array}$ & PTA $_{\mathbf{0 . 5 , 1 , 2 , 4}}$ & PTA $_{3,4, \mathbf{6}}$ \\
\hline $\begin{array}{l}\text { Internet test } \\
\text { 1 MED-EL }\end{array}$ & - & $0.177^{* *}$ & $0.150^{*}$ & $0.159^{*}$ \\
\hline $\begin{array}{l}\text { Internet test } \\
\text { 2 NHS }\end{array}$ & $0.177^{* *}$ & - & 0.002 & 0.019 \\
\hline $\mathrm{PTA}_{0.5,1,2,4}$ & $0.150^{*}$ & 0.002 & - & $0.188^{* *}$ \\
\hline $\mathrm{PTA}_{3,4,6}$ & $0.159^{*}$ & 0.019 & $0.188^{* *}$ & - \\
\hline
\end{tabular}

Table 10: Bivariate correlation coefficients (Spearman's rho) for internet-based hearing screening test and PTA-values.

*., **. Correlation is significant at the 0.05 and 0.01 level (2-tailed) respectively.

\begin{tabular}{|l|c|c|c|}
\hline PTA & Internet test & Sensitivity & Specificity \\
\hline \multirow{2}{*}{ PTA $_{0.5,1,2,4}$} & Test 1 & $82.4 \%$ & $95.6 \%$ \\
\cline { 2 - 4 } & Test 2 & $47.0 \%$ & $52.6 \%$ \\
\hline \multirow{2}{*}{ PTA $_{3,4,6}$} & Test 1 & $81.3 \%$ & $95.6 \%$ \\
\cline { 2 - 4 } & Test 2 & $43.8 \%$ & $52.4 \%$ \\
\hline
\end{tabular}

Table 11: Sensitivity and specificity of internet-based hearing screening tests in relation to pure-tone averages $\left(\mathrm{PTA}_{0.5,1,2,4}\right.$ and

$$
\left.\mathrm{PTA}_{3,4,6}\right) \text {. }
$$

PTA results of hearing threshold frequency from 125 to 8000 $\mathrm{Hz}$ showed almost three-fourths of the study participants had no hearing loss. Total percentage of hearing loss (minor, moderate and severe) was $26.1 \%$. When findings of PTA averages and results of internet-based hearing screening tests (internet test 1 and 2) were compared, there was no difference between hearing status and socio-demographic characteristics and hearing tests ( $p>0.1$ ). However, the Chi-square test showed this difference to be statistically significant $(\mathrm{p}<0.05)$ between internet test and PTA for other factors such as hearing loss among ethnicity, Hearing loss Vs Past history of ear problem, Hearing loss Vs Number of years using mobile phone and, Normal hearing Vs Ear using mobile phone. Non-parametric Spearman correlation coefficients was calculated for the relationship between internet-based hearing screening test (internet test 1 and 2 ) and PTA averages $\left(\mathrm{PTA}_{0.5,1,2,4}\right.$ and $\left.\mathrm{PTA}_{3,4,6}\right)$. A significant correlation existed between PTA and internet test 1 results but it was not significant for internet test 2 (Table 10). More than half of the participants had been using a mobile phone for $\geq 2$ hours per day for more than 5 years. Only $8.2 \%$ of them had tinnitus associated with mobile/headphone use revealing a significant difference both on PTA and internet test $1(\mathrm{p}=0.019)$ (Table 8). YANS was employed to assess the participant's attitudes to noise exposure. Factor analysis revealed the four main attributing factors: (F1) noise associated with youth culture (e.g. loud music at concerts or discos); (F2) ability to concentrate in a noisy environment; (F3) daily noises (e.g. traffic noise); (F4) influencing the sound environment. While half of them showed neutral attitude, $25 \%$ had pro-noise and the remaining $25 \%$ had anti-noise attitude according to the quartiles of the sum of the entire YANS scale. The comparative findings of present study showed that result of the internet test 1 was more comparable to PTA averages than internet test 2 .

\section{Discussion}

Prevalence of hypoacusis among participants were reported using pure tone audiogram (PTA) at 125, 250, 500, 1000, 2000, 3000, 4000,6000 and $8000 \mathrm{~Hz}, 64$ out of 245 (26.1\%) had hearing loss. Of these $61(24.9 \%)$ had minor hearing loss, $2(0.8 \%)$ had moderate, and $1(0.4 \%)$ had severe hearing loss, according to the definition 
by WHO classification of hearing loss [11]. This suggests a subset of the current subjects had hearing loss that they were not aware of. Since, the present study included the participants with self-reporting normal hearing sensitivity. This is similar to that found by Widén et al who reported a $26 \%$ referral rate from a college-aged student sample (258 American undergraduates) using a $20 \mathrm{~dB} \mathrm{HL}$ pass criterion at $0.5,1,2,4$ and $6 \mathrm{kHz}$ [12]. Similar sub-clinical deficits of hearing loss in normal young individuals were observed in the previous reports [13,14].The present study showed $26.1 \%$ hearing loss with PTA at cut-off level of $25 \mathrm{~dB}$. By using PTA at a cutoff level of $25 \mathrm{~dB}$, the prevalence of hearing loss was $24.3 \%$ among elderly Malaysians which is consistent with our PTA results [15]. The prevalence of hearing loss in Malaysia remains more than the WHO estimate. Nevertheless, the current study measured the hearing status of young population (18 - 40 years) and compared the audiometric findings to internet-based hearing screening test. The DTT (digit triplet test) using a signal-in noise rationale is the most documented telephone/internet based test. Smartphone applets are the latest trend in platforms for hearing screening [16].

Present study of internet-based hearing screening test showed $5.3 \%$ hearing loss with internet test 1 and $47.3 \%$ hearing loss with internet test 2. Using the conventional screening (PTA), as a gold standard, the specificity of the internet-based hearing screening test was low, based on the overall screening data. When 125 and $250 \mathrm{~Hz}$ results were excluded, the specificity of the internet test improved in value. Taking a $25 \mathrm{~dB}$ hearing loss (HL) as a baseline average, by PTA for frequencies at 500, 1000, 2000, 3000, 4000, 6000 and $8000 \mathrm{~Hz}$, the prevalence of hearing loss among participants was reduced to $11.8 \%$. This figure is in agreement with internet-based hearing screening test. This is consistent with the previous comparison study of computer-based and conventional audiometry in school children [17].

In the previous study of internet-based hearing test with study population (20-60 years) with high exposure to impulse noise, showed high prevalence (52\%) of hearing impairment [18]. Although our result from the internet-based hearing screening test 2 showed a prevalence of $47.6 \%$ hearing loss, which indicates high prevalence for aged between 18 to 40 years. Since the present study population is not an excessive noise exposure group, the prevalence of hearing loss with internet test 2 seems to be higher, probably due to the lower sensitivity and specificity of the internet test 2 (Table 11).
For speech intelligibility $\left(\mathrm{PTA}_{0.5,1,4,4}\right)$ and noise-sensitive frequencies $\left(\mathrm{PTA}_{3,4,6}\right)$, internet-based screening test 1 was comparable to the conventional screening instrument (Table 9). Previous study reported the difference between speech intelligibility of participants with noise-induced hearing loss and normal hearing [19]. The results of present comparison study revealed that internetbased hearing screening (speech-in-noise) test differentiated between normal hearing and hearing loss. The internet test 1 proves to yield reliable results. The internet test 2 was not strongly related to pure-tone thresholds, whereas PTA gives accurate hearing threshold result for each frequency. In the present study, there was no difference in normal-hearing and hearing loss with respect to age that is contrary to the previous studies [20].

Earlier report by Plomp and Mimpen observed that the hearing loss subjects had a mean age of 56 years [21]. This corresponds to a median speech reception threshold (SRT) of only $1 \mathrm{~dB}$ poorer than the median SRT for the young normal-hearing subjects. Age range of current study participants was between 18 to 40 years. Poor speech-in-noise recognition was rare in this age range.

In the present study, the correlation coefficients (Spearman's rho) of test validity for internet-based hearing screening test are $0.150-0.159$ for internet test 1 and $0.002-0.019$ for internet test 2 (Table 10). Previous studies done in Netherland using Dutch language reported moderately high correlation coefficients of 0.72 - 0.84 between results of the speech-in-noise test and pure-tone averages for normal hearing and hearing-impaired listeners [22]. The findings of Leensen $e t a l^{19}$ showed similar correlations; $r$ is 0.82 comparing the results of the speech-in-noise test with PTA averages $\left(\mathrm{PTA}_{0.5,1,2,4}\right.$ and $\left.\mathrm{PTA}_{2,4}\right)$. Although the correlation coefficients between results of each internet test and PTA averages (both PTA $_{0.5,1,2,4}$ and PTA ${ }_{3,4,6}$ of the present study was low, all the correlations between internet test 1 and PTA-averages were statistically significant (Table 10). Lower correlation coefficient in the present study is probably due to English version of the speech-in-noise tests and it was done on bilingual Malaysian adults who acquired English as a second language.

Sensitivity and specificity of the internet test 1 are $~ 81 \%$ and $95.6 \%$ respectively, which is higher than the previous study of speech-in-noise test (a Digit Triplet test) in which specifically in noise-exposed workers was investigated by Leensen et al and reported sensitivity and specificity values of $55 \%$ and $94 \%$, respectively [20]. The reason for these rather weak results may be due to the stimuli that were employed. 
Statistical significance was found among the underlying factors (personal habits, exposure to noise, tinnitus and attitudes towards noise) with audiometric findings and/or internet-based hearing screening tests. Several factors might have contributed to this outcome. A weak but significant association between smoking and hearing loss in the elderly has been reported previously [23]. The effect was only found in males, not in females, suggesting that the effect of smoking was sex-dependent. In the current study, we could not find the effect of gender and smoking on hearing status as there were no female smokers among the study participants. Personal habits (alcohol drinking, regular physical activity) had no significant difference between normal and hearing loss in both PTA and internet-based hearing screening test.

For the exposure to noise, there was association of the number of years using mobile phone and duration of tinnitus between normal and hearing loss (Table 8). Duration of use of mobile phone with respect to number of years and internet test 2 showed statistically significant difference with $\mathrm{PTA}_{0.5,1,2,4}$ in hearing loss (Table 8). Many earlier reports have suggested that exposure to mobile phone microwaves has no influence on the activity of cochlear outer hair cells or of cochlear nerve electrical conduction, both in vivo and in vitro [24-26]. But, our results from the internet test 2 showed statistically significant difference with $\mathrm{PTA}_{3,4,6}$ in normal hearing group (ear use for mobile phone). For internet test 1, the Chi-square test showed statistically significant difference between PTA $_{0.5,1,2,4}$ and normal hearing in variable group (the number of years using mobile phone) ( $p=0.012)$ which is in correlation with the previous study [27]. Since only PTA measurements were done on normal-hearing subjects in the present study, it is not possible to conclude at this stage whether the cochlea of subjects with inner ear conditions would be more sensitive to mobile phone electromagnetic radiation.

In this study, participants had self-reported normal hearing. According to the research questionnaire, prevalence of tinnitus (ringing in the ear) after mobile/headphone use was found in 20 participants of the study (8.2\%) and among them, most had tinnitus sometimes (4.5\%), 2\% had occasionally, and $2.9 \%$ had tinnitus most of the times after using the mobile phone. None of our subjects reported permanent tinnitus. The percentage of observed tinnitus in the present study is comparable to other studies $[9,11]$.

The YANS questionnaire has been used in many countries, including Sweden, USA, China and Brazil [28-30]. To the best of our knowledge, the present study reports the first adaption of YANS for
Malaysian population. The current study indicates that the Bahasa Melayu version of YANS is valid and reliable (Cronbach's alpha general $=0.533$ ) $($ Table 11$)$, lower than the earlier results in USA (0.82) and Brazil $(0.75)[28,29]$. The distribution of factors in our factorial analysis differs slightly from previously published YANS studies. Notably, the mean overall YANS score (2.65) in our study was lower than Belgium (3.10), Brazil (2.80) and China (3.46) but higher than Sweden $(2.10)[9,28,30,32]$. Overall mean YANS score showed most of our study participants had positive attitude towards noise. This study indicates that the lesser validity and reliability of Bahasa Melayu version of YANS (Cronbach's alpha general $=0.533$ ), compared to other study results. The possible reason for this may be due to sample size. Since there were more women than men in our study, the difference between average YANS scores of both genders was not statistically significant, which is consistent with the results in Chinese [31,32].

\section{Conclusion}

With the results that has been obtained and analysed, there is evidence to support that the self-administered internet-based hearing screening test is approximately similar in comparison to the gold standard hearing assessment with PTA with high sensitivity and specificity with few limitations. Hearing health education must develop programs to educate youth on the potential implications of noise exposure. Hence, this study suggests internet-based hearing test as an alternative test to PTA is feasible to screen for hearing status online. Large-scale investigation is required to compare the internet-based hearing screening test among normalhearing and hearing impaired individual in various age-groups with measured speech recognition threshold (SRT) to confirm our findings and further to explore the significance of additional findings. Test-retest of YANS questionnaire considered as a screening instrument for identifying individuals who might be at risk for developing hearing damage would be a task for future research.

\section{Acknowledgement}

The authors are thankful to AIMST University for extending the required facilities to carry out this research project.

\section{Conflict of Interest}

Authors declare no conflicts of interest.

\section{Bibliography}

1. World Health Organization. WHO global estimates on prevalence of hearing loss (2012). 
2. Chadha S., et al. "Global hearing health: future directions". Bulletin of the World Health Organization 96.3 (2018): 146.

3. Ismail AF., et al. "Noise-induced hearing loss among quarry workers in a north-eastern state of Malaysia: a study on knowledge, attitude and practice". Oman Medical Journal 28.5 (2013): 331.

4. $\quad$ Rashid MS and Dreschler WA. "Accuracy of an internet-based speech-in-noise hearing screening test for high-frequency hearing loss: incorporating automatic conditional rescreening". International Archives of Occupational and Environmental Health 91.7 (2018): 877-885.

5. Sulaiman AH., et al. "Evaluation of early hearing damage in personal listening device users using extended high-frequency audiometry and otoacoustic emissions". European Archives of Oto-Rhino-Laryngology 271.6 (2014): 1463-1470.

6. De Wet Swanepoel KC., et al. "Mobile applications to detect hearing impairment: opportunities and challenges". Bulletin of the World Health Organization 97.10 (2019): 717.

7. Chu YC., et al. "A Mobile Phone-Based Approach for Hearing Screening of School-Age Children: Cross-Sectional Validation Study". JMIR mHealth and uHealth 7.4 (2019): e12033.

8. Daud MK., et al. "The effect of mild hearing loss on academic performance in primary school children". International Journal of Pediatric Otorhinolaryngology 74.1 (2010): 67-70.

9. Widén SO and Erlandsson SI. "The influence of socio-economic status on adolescent attitude to social noise and hearing protection". Noise and health 7.25 (2004): 59.

10. Mathers C., et al. "Global burden of hearing loss in the year 2000". Global burden of Disease 18.4 (2000): 1-30.

11. Olusanya BO., et al. "Hearing loss grades and the International classification of functioning, disability and health". World Health Organization. Bulletin of the World Health Organization 97.10 (2019): 725-728.

12. Widen SE., et al. "Hearing, use of hearing protection, and attitudes towards noise among young American adults". International Journal of Audiology 48.8 (2009): 537-545.

13. Niskar AS., et al. "Prevalence of hearing loss among children 6 to 19 years of age: the Third National Health and Nutrition Examination Survey". JAMA 279.14 (1998): 1071-1075.

14. Le Prell CG., et al. "Evidence of hearing loss in a 'normallyhearing'college-student population". International Journal of Audiology 50.1 (2011): S21-31.
15. Rosdina AK., et al. "Self-reported hearing loss among elderly Malaysians". Malaysian family physician: The Official Journal of the Academy of Family Physicians of Malaysia 5.2 (2010): 91.

16. Stenfelt S., et al. "e-Health technologies for adult hearing screening”. Audiology Research 1.1 (2011): 25-28.

17. McPherson B., et al. "Hearing screening for school children: comparison of low-cost, computer-based and conventional audiometry". Child: Care, Health and Development 36.3 (2010): 323-331.

18. Bexelius C., et al. "Evaluation of an internet-based hearing testcomparison with established methods for detection of hearing loss". Journal of Medical Internet Research 10.4 (2008): e32.

19. Leensen MC., et al. "Speech-in-noise screening tests by internet, part 1: Test evaluation for noise-induced hearing loss identification". International Journal of Audiology 50.11 (2011): 823-834.

20. Leensen MC., et al. "Speech-in-noise screening tests by internet, part 2: improving test sensitivity for noise-induced hearing loss". International Journal of Audiology 50.11 (2011): 835848.

21. Plomp R and Mimpen AM. "Speech-reception threshold for sentences as a function of age and noise level". The Journal of the Acoustical Society of America 66.5 (1979): 1333-1342.

22. Smits C., et al. "Development and validation of an automatic speech-in-noise screening test by telephone". International Journal of Audiology 43.1 (2004): 15-28.

23. Rosenhall U., et al. "Correlations between presbyacusis and extrinsic noxious factors". Audiology 32.4 (1993): 234-243.

24. Aran JM., et al. "Effects of exposure of the ear to GSM microwaves: in vivo and in vitro experimental studies". International Journal of Audiology 43.9 (2004): 545-554.

25. Oysu C., et al. "Effects of the acute exposure to the electromagnetic field of mobile phones on human auditory brainstem responses". European Archives of Oto-Rhino-Laryngology and Head and Neck 262.10 (2005): 839-843.

26. Sievert U., et al. "Can mobile phone emissions affect auditory functions of cochlea or brain stem?" Otolaryngology-Head and Neck Surgery 132.3 (2005): 451-455.

27. Oktay MF and Dasdag S. "Effects of intensive and moderate cellular phone use on hearing function". Electromagnetic Biology and Medicine 25.1 (2006): 13-21. 
28. Zocoli AM., et al. "Brazilian young adults and noise: attitudes, habits, and audiological characteristics". International Journal of Audiology 48.10 (2009): 692-699.

29. Widén SE., et al. "Reported hearing protection use in young adults from Sweden and the USA: Effects of attitude and gender: Reportes de uso de protección auditiva en jóvenes adultos en Suecia y en los EUA: Efectos de actitud y de género". International Journal of Audiology 45.5 (2006): 273-280.

30. Zhu X., et al. "Chinese-adapted youth attitude to noise scale: Evaluation of validity and reliability". Noise and Health 16.71 (2014): 218.

31. Gilles A., et al. "Epidemiology of noise-induced tinnitus and the attitudes and beliefs towards noise and hearing protection in adolescents". PloS One 8.7 (2013): 24-29.

32. Degeest S., et al. "The test-retest reliability of questionnaires regarding attitudes and beliefs toward noise, hearing loss, and hearing protector devices in young adults". Noise and Health 20.93 (2018): 31.

\section{Assets from publication with us}

- Prompt Acknowledgement after receiving the article

- Thorough Double blinded peer review

- Rapid Publication

- Issue of Publication Certificate

- High visibility of your Published work

Website: www.actascientific.com/

Submit Article: www.actascientific.com/submission.php

Email us: editor@actascientific.com

Contact us: +919182824667

Citation: Usha Kumari., et al. "Comparison of Audiometric Findings with Internet-based Hearing Screening Tests and the Relationship with Other Associated Factors in Adults". Acta Scientific Medical Sciences 4.12 (2020): 103-113. 